\title{
The Impact of Addiction on Academic Performance of Students: the Case of Wolaita Sodo University, Ethiopia
}

Elias Bojago ( $\sim$ eliasboja77@gmail.com )

Wolaita Sodo University College: Wolaita Sodo University https://orcid.org/0000-0002-7235-8760 Abenezer Wendimu

Wolaita Sodo University

\section{Research}

Keywords: Addiction, Academic performance, Education, Globalization, Students, Stimulants, Technological advancement

Posted Date: August 4th, 2021

DOI: https://doi.org/10.21203/rs.3.rs-743863/v1

License: (c) (i) This work is licensed under a Creative Commons Attribution 4.0 International License. Read Full License 


\title{
The impact of addiction on academic performance of students: the case of Wolaita Sodo
} University, Ethiopia

\author{
Elias Bojago*a and Abenezer Wendimu $^{\mathrm{b}}$
}

${ }^{a}$ Department of Environmental Science, College of Natural and Computational Sciences, Wolaita Sodo University, Wolaita Sodo, Ethiopia

${ }^{b}$ Department of Biology, College of Natural and Computational Sciences, Wolaita Sodo University, Wolaita Sodo, Ethiopia

Corresponding author e-mail address: eliasboja@gmail.com

Running title: Impact of addiction on academic performance of students

\begin{abstract}
Background: The high prevalence of substance use and its association with poor academic performance is a global concern today. Objective: The study was conducted to assess the impact of addiction on the academic performance of students in the case of Wolaita Sodo University. Methods: Cross-sectional study was carried out among a total of 421 students selected by using the cluster sampling technique. Data were collected via semistructured questionnaires and interviews and analyzed using descriptive and inferential statistics. Results: The results showed that, from the total sample of students, $71.8 \%$ of the respondents were involved in addiction while the rest $28.2 \%$ were free from any addiction and $73.1 \%$ males were more likely to be addicted than females (26.9\%). The chi-square result also shows that addiction and academic performance were found to be dependent and addicted students were associated with poor academic achievement than nonaddicted. The regression dummy variable test also showed that the students involved in addiction recorded a lower academic results by 0.587 than addiction free students. Conclusion: Behavioral and physiological addiction to illicit substances and other stimulants is common in Wolaita Sodo University as in other higher education institutions. The common practice of substance use and its association with poor academic performance demand universities to have a good control of the substance and to implement youth friendly activities. The effects of addiction might be better studied through pertinent, vigorous research.
\end{abstract}

Key words: Addiction, Academic performance, Education, Globalization, Students, Stimulants, Technological advancement

\section{INTRODUCTION}


At the current level of globalization and technological advancement, education is a paramount step on which every human activity depends on. It plays a vital role in the development of human capital and has a great linkage with an individual's well-being and opportunities for better living. Education is one of the most important social institutions that prepare students formally for entry into society and it is an agent of socialization. It is a fundamental human right as well as a catalyst for economic growth and human development [1]. Due to these reasons, different nations of the world gave an emphasis to education to solve the social problems by producing dynamic and extraordinary generations through the process of education.

In support of this idea, Ethiopia launched a school improvement program to improve the factors that affect the quality of education through enhancing student learning and achievement [2]. Accordingly, educators, trainers, and researchers have long been interested in exploring factors and variables contributing effectively to the academic achievement of learners. These factors and variables can be inside and outside of school.

Different factors like addiction, socioeconomic background of the student's parents, and different social related values and students' attitudes towards education are found to be the most common factors that influence the academic achievement of students. However, according to Aklog and Girmay [3], substances are practiced by students regardless of its negative consequences. The practice of using psycho-active substances from plant origins such as khat (Catha edulis, which is East African common evergreen plant leave), products of tobacco (cigarette, shisha), and alcoholic drinks (Areki, Tej) has become an increasingly evident public health concerns and the cause of low grading in education [4].

Historically, addiction has been defined as physical and psychological dependence on psychoactive substances that cross the blood-brain barrier once ingested, temporarily altering the chemical setting of the brain. It is chronic, but not incurable. Drug addicted groups of people face difficulties to control their need for drugs and alcoholic products regardless of its harmful effects on health and social relationships. The problem related to lack of control were considered the result of alcohol or other drug induced changes in the brain setting. The changes happened to the brain settings causing offensive behavioral changes [5]. 
Addiction is caused by different stimulants. These are psychoactive drugs, computer games, social network, and illicit pornographic contents which induce temporarily improvements in either mental or physical function or both, i.e. increase activity in the brain, temporarily, elevate alertness mood and awareness for short periods of time. Additionally, speed up the signals passing throughout the central nerve system, heart rate, breathing rate, neurological disorders, and brain function [6].

Irrespective of substance use and its association with poor academic performance, students practice different kinds of substances to have good academic achievement [3]. According to Bakar et al.[7], the substance was practiced by a not insignificant proportion of university students in Turkey; $24.8 \%$ of students regularly smoke cigarettes, $37.8 \%$ drunk alcohol occasionally, and by $8.1 \%$ of students in a regular basis. Other similar studies in Iran reported the use of a substance (alcohol, cigarettes, and water pipes) by students (22\% male and $8 \%$ female medical students) at least once in their lives [8]. According to van Heerden et al.. [9], the use of alcohol was $38.7 \%$, tobacco smoking $30 \%$, and cannabis was $8.4 \%$ in South Africa.

In Ethiopia, different substances like khat, alcohol, and other tobacco products have been used by significant proportions of university students. Among the students of Addis Ababa and Axum University, the lifetime prevalence of khat use was $14.1 \%$ and $27.9 \%$, respectively [10] [11]. The lifetime prevalence of cigarette smoking in the same universities was $12.494 \%$ and $8.7 \%$; of those, $4.2 \%$ and $1.8 \%$ were daily smokers, respectively [10] [11]. Other similar studies showed the prevalence of khat chewing among high school students in eastern Ethiopia [12].

Since the proportion of the student population in higher educational institutions is increasing, substance use and its association with academic performance are going to be an increasing concern. As a good alert for universities and policymakers about the impact of drug use on academic performance; the results will play an important role in taking evidence-based action interventions. Therefore, the major purpose of this study is to evaluate the prevalence of substance use among college students and its relationship with academic performance.

Alcohol, cigarettes, khat, computer games, internet, social networks, and porn are the most and common types of addictions in Ethiopian higher education institutions and the trend is similar in Wolaita Sodo University. To meet the needs of students, residents around the the university 
produce or supply stimulants such as alcoholic drinks and khat. Therefore, the present study was carried out to investigate the ill effects of adduction on student's academic performance in Wolaita Sodo University main campus.

\section{MATERIALS AND METHOD}

\section{Description of the Study Area}

The study was carried out in Wolaita Sodo University in the academic year of 2020/2021. The university is approximately 339 kilometers (210.65 miles) far from Addis Ababa, Ethiopia, in the southwest direction. Specifically, it is found in Wolaita Zone, capital town of Sodo, with coordinates $\left(6^{\circ} 49^{\prime} 44.6^{\prime \prime} \mathrm{N}\right.$ latitude and $37^{\circ} 45^{\prime} 03.5^{\prime \prime} \mathrm{E}$ longitude). It is one of the second generation universities of Ethiopia. The university has three campuses: Gandaba campus, Otona campus, and Tercha campus. Currently, Wolaita Sodo University operates 58 undergraduate programs, 43 postgraduate programs , 6 doctor of philosophy programs, and 4 medical specialty programs.

\section{Sources of Data}

Both primary and secondary sources of data were used in the study to obtain detailed data about the problem under investigation. The primary data was collected from students directly. The secondary data was collected from different published documents and university register office student database.

\section{Selection of Respondents}

The respondents were selected using a systematic random sampling technique. An individual who believed himself is addicted to more than one type of stimulants and has used social networks through the internet at least once in the last two weeks was got the priority to participate in the study.

\section{Data gathering instruments}

The study was used mixed methods (questionnaire, interview and focus group discussion) to collect the appropriate inputs. The tool used for quantitative data was self-administered 
questionnaire through paper or already prepared telegram but to collect information from the respondents on the effects of addiction on academic performance.

\section{Sample Size Determination and Sampling Techniques}

In the present study, the cluster sampling technique was utilized. It is a sampling technique used when "natural" groupings are clear in statistical populations. The study participants were only second year regular students. The total population was recruited by different clusters (colleges) and participants in each smaller cluster (departments) were selected based on their availability and willingness. Assuming a fixed sample size, the technique gives results that are more exact when most of the variation in the population is within the groups, not between them. A stratified sampling technique is then employed on the relevant clusters to distribute the number of samples in each selected department. The procedure are as follows:-

Let $M=$ number of clusters (colleges) in university, where $M=9$, then to find the smallest cluster (department) from $\mathrm{M}$ which is denoted by small $\mathrm{m}$. The study takes the population proportion $50 \%$ due lack of earlier study and difficult to conduct a pilot survey within $10 \%$ largest allowable margin of error to find the sample size from the target population.

$$
\begin{gathered}
m=\frac{Z_{1-\frac{\alpha}{2}}^{2} M P(1-P)}{Z_{1-\frac{\alpha}{2}}^{2} P Q+(m-1) d^{2}} \\
\text { Where, } Z \alpha / 2=Z 0.05=1.96 \\
\mathrm{~d}=0.10 \\
\mathrm{P}=0.50 \& \mathrm{Q}=1-\mathrm{P}=0.50 \\
m=\frac{(1.96)^{\wedge} 2(9)(0.5)(0.5)}{(1.96)^{2}(0.5)(0.5)+(9-1)(0.10)^{2}}=5
\end{gathered}
$$

One department from each of the five colleges were selected by simple random sampling. Here, the total sample size was calculated as follows:-

$$
\begin{gathered}
n_{o}=\frac{\llbracket z_{a / 2}+z_{B} \rrbracket \wedge 2 * P Q}{d^{2}} \\
z_{B}=1-Z_{a / 2}
\end{gathered}
$$




$$
\begin{gathered}
\text { Where; } \\
n_{o}=\frac{(1.96+0)^{2}(0.5)(0.5)}{(0.10)^{2}}=96 \\
n=\frac{n_{o}}{1+\frac{n_{o}}{N}}=\frac{96}{1+\frac{96}{421}}=78
\end{gathered}
$$

Table 1: The sample size of study population

\begin{tabular}{|l|l|l|l|l|}
\hline No. & Colleges & Departments & Total population & Sample size \\
\hline 1. & Natural and Computational & Environmental Science & 55 & 10 \\
\hline 2. & Agriculture & Agro-Economics & 162 & 30 \\
\hline 3. & Informatics & Information system & 64 & 12 \\
\hline 4. & Social science & Accounting and finance & 81 & 15 \\
\hline 5. & Engineering & Construction management & 59 & 11 \\
\hline Total & & 421 & 78 \\
\hline
\end{tabular}

\section{DATA ANALYSIS}

The collected data was analyzed by using descriptive and inferential statistics. The descriptive statistics tool used was a table of different data types. The most appropriate inferential statistics that this study used was; chi-square test of dependency to check the association between the dependent and independent variables, analysis of variance (ANOVA) to ensure weather, the overall regression model is significant or not and regression on dummy variables to test if the academic performance of students that use stimulants or caused by addiction is differ from the academic performance of the students that do not use stimulants or do not caused by addiction.

\section{RESULTS}

There were 78 students who took part in the present study. They were selected from different colleges and departments of Wolaita Sodo University. The participants were only second year regular students. The colleges selected were; College of Natural and Computational Sciences, College of Agriculture, Informatics College, College of Social Science and Humanity and College of Engineering. The departments were environmental studies, agro-economics, information system, accounting, and finance and construction management (COTM) (Table 1).

Table 2: Sex distribution of respondents

\begin{tabular}{|l|l|l|l|}
\hline Variables & Frequency & Percent $(\boldsymbol{\%})$ \\
\hline Sex & Female & 21 & $26.9 \%$
\end{tabular}




\begin{tabular}{|l|l|l|l|}
\hline & Male & 57 & $73.1 \%$ \\
\cline { 2 - 4 } & Total & 78 & $100.0 \%$ \\
\hline
\end{tabular}

Table 2 shows that most of the respondents were male 57(73.1\%) compared to female respondents $21(26.9 \%)$ in the present study. Males were participated in the study more than females.

Table 3: The distribution of addiction and non-addiction

\begin{tabular}{|l|l|l|l|}
\hline Variables & Response & Frequency & Percent (\%) \\
\hline Addictive's & No & 22 & $28.2 \%$ \\
\cline { 2 - 4 } & Yes & 56 & $71.8 \%$ \\
\cline { 2 - 4 } & Total & 78 & $100.0 \%$ \\
\hline
\end{tabular}

Table 3 shows that from the respondents (78) selected systematically based on their vulnerability to addiction, 56(71.8\%) were found to be evolved in one or more types of addictions while the rest 22(28.2\%) were found to be addicted to not any substance and free from any type of addiction. The number of respondents practicing addiction directly or indirectly is much greater than respondents not aware of any addiction practices.

Table 4: Distribution of the type of stimulants students use

\begin{tabular}{|l|l|l|l|}
\hline No & Types of stimulants & Frequency & Percent (\%) \\
\hline 1 & Social networks and porn & 15 & $26.8 \%$ \\
\hline 2 & Khat & 9 & $16.1 \%$ \\
\hline 3 & Computer games & 4 & $7.1 \%$ \\
\hline 4 & Alcohol & 10 & $17.9 \%$ \\
\hline 5 & Coffee & 18 & $32.1 \%$ \\
\hline
\end{tabular}

Table 4 shows that most of the respondents were found to be addicted to various kinds of stimulants based on preference. Most of the respondents $18(32.1 \%)$ were found to use coffee before or after class every day. The minimum number $4(7.1 \%)$ of the respondents were addicted to computer games where as 15(26.8\%), 10 (17.9\%), and 9 (16.1\%) identified as khat, alcohol and porn and other social networks respectively. Consumption of coffee is a common and widely available stimulant for students in the university.

Table 5: The distribution of reason of using stimulants 


\begin{tabular}{|l|l|l|l|}
\hline Variables & Reason & Frequency & Percent \\
\hline Reasons of using stimulants & Spending time & 5 & 8.9 \\
\cline { 2 - 4 } & To improve reading \& understanding & 18 & 32.1 \\
\cline { 2 - 4 } & For refreshment (relax and enjoy) & 32 & 55.4 \\
\cline { 2 - 4 } & Peer pressure & 2 & 3.6 \\
\hline
\end{tabular}

Table 5 shows, most of the respondents 31(55.4\%) use stimulants to refresh themselves and the minimum number $2(3.6 \%)$ of respondents filled in addiction by the encouragement of their friends were as $18(32.1 \%), 5(8.9 \%)$ are use stimulants to improve reading and understanding and to spend there time, respectively. Most of the respondents use stimulants for refreshment to get relaxation and enjoyment.

\section{Chi-Square Test of Intendance}

The result Chi-Square Test of intendance shows that whether the variables have association or not at $5 \%$ level of significance.

Table 6: Sex of the respondents and academic performance of respondents

\begin{tabular}{|l|l|l|l|}
\hline \multicolumn{4}{|c|}{ Chi-Square Tests } \\
\hline Tests & Value & df & Asymp. Sig. (2-sided) \\
\hline Pearson Chi-Square & $6.727 \mathrm{a}$ & 3 & 0.081 \\
\hline Likelihood Ratio & 7.426 & 3 & 0.059 \\
\hline Linear-by-Linear Association & 5.645 & 1 & 0.018 \\
\hline N of Valid Cases & 78 & & \\
\hline
\end{tabular}

Table 6 shows that the sex of respondents and their academic performance are independent of the level of significance $(\mathrm{P}=0.081)$ and there is no linear association between them.

Table 7: Average monthly income of respondents and academic performance of respondents

\begin{tabular}{|l|l|l|l|}
\hline \multicolumn{4}{|c|}{ Chi-Square Tests } \\
\hline Tests & Value & df & Asymp. Sig. (2-sided) \\
\hline Pearson Chi-Square & $15.833 \mathrm{a}$ & 12 & 0.0199 \\
\hline Likelihood Ratio & 12.494 & 12 & 0.0407 \\
\hline Linear-by-Linear Association & 2.667 & 1 & 0.0102 \\
\hline N of Valid Cases & 78 & & \\
\hline
\end{tabular}

Table 7 shows that the academic performances of respondents and there income are interdependent $(\mathrm{P}=0.0199)$ and there is an association between income of respondents to there 
acacademic achievements. Lack of enough finance halts the need of students and makes them dependent on other students of similar academic level.

Table 8: Time spent for the study and academic performance of respondents

\begin{tabular}{|l|l|l|l|}
\hline \multicolumn{4}{|c|}{ Chi-Square Tests } \\
\hline Tests & Value & df & Asymp. Sig. (2-sided) \\
\hline Pearson Chi-Square & $24.785 \mathrm{a}$ & 9 & 0.003 \\
\hline Likelihood Ratio & 22.558 & 9 & 0.007 \\
\hline Linear-by-Linear Association & 16.200 & 1 & 0.000 \\
\hline N of Valid Cases & 78 & & \\
\hline
\end{tabular}

Table 8 shows that the academic performance and the time given for the study are dependent (P $=0.003$ ) and there is a perfect association between them. Students spend more time in the study, academic achievement becomes good as well.

Table 9: Addictive substances and academic performance of respondents

\begin{tabular}{|l|l|l|l|}
\hline \multicolumn{4}{|c|}{ Chi-Square Tests } \\
\hline Tests & Value & df & Asymp. Sig. (2-sided) \\
\hline Pearson Chi-Square & $16.073 \mathrm{a}$ & 3 & 0.001 \\
\hline Likelihood Ratio & 17.865 & 3 & 0.000 \\
\hline Linear-by-Linear Association & 15.059 & 1 & 0.000 \\
\hline N of Valid Cases & 78 & & \\
\hline
\end{tabular}

Table 9 shows that the use of stimulants and academic performance are dependent $(\mathrm{P}=0.001)$. Addictions highly influenced students' academic performance.

Table 10: Different types of stimulants that the respondents use and there association with student academic achievement

\begin{tabular}{|l|l|l|l|}
\hline \multicolumn{4}{|c|}{ Chi-Square Tests } \\
\hline Tests & Value & df & Asymp. Sig. (2-sided) \\
\hline Pearson Chi-Square & $26.490 \mathrm{a}$ & 12 & 0.009 \\
\hline Likelihood Ratio & 25.756 & 12 & 0.012 \\
\hline Linear-by-Linear Association & 3.915 & 1 & 0.048 \\
\hline N of Valid Cases & 56 & & \\
\hline
\end{tabular}

Table 10 shows that different types of stimulants that a student's use and their academic performance are dependents $(\mathrm{P}=0.04)$. Stimulants have a direct relationship with the academic achievement of students. 


\section{Regression Dummy Variable Test}

Table 11: Analysis of Regression Variable

\begin{tabular}{|l|l|l|l|l|l|}
\hline \multicolumn{5}{|c|}{ Model Summary } \\
\hline Model & $\mathrm{R}$ & R Square & Adjusted R Square & $\begin{array}{l}\text { Std. Error of the } \\
\text { Estimate }\end{array}$ & Durbin-Watson \\
\hline 1 & $0.542 \mathrm{a}$ & 0.293 & 0.275 & 0.725 & 2.048 \\
\hline
\end{tabular}

Table 11 shows R-square and Adjusted R-square is 0.293 and 0.275 , respectively. The value of R-squared adjusted is 0.275 showing $27.5 \%$ of the variability of the academic performance of the students explained by the factors included in the model. Moreover, the Durbin-Watson statistics which is equals to 2.048 implies that there is no autocorrelation that affects our model.

Table 12: Coefficients determination

\begin{tabular}{|c|c|c|c|c|c|c|c|c|}
\hline \multicolumn{9}{|c|}{ Coefficients } \\
\hline \multirow{2}{*}{\multicolumn{2}{|c|}{ Model }} & \multicolumn{2}{|c|}{$\begin{array}{l}\text { Unstandardized } \\
\text { Coefficients }\end{array}$} & $\begin{array}{l}\text { Standardized } \\
\text { Coefficients }\end{array}$ & \multirow[t]{2}{*}{$\mathrm{t}$} & \multirow[t]{2}{*}{ Sig. } & \multicolumn{2}{|c|}{$\begin{array}{l}\text { Collinearity } \\
\text { Statistics }\end{array}$} \\
\hline & & $\mathrm{B}$ & Std. Error & Beta & & & Tolerance & VIF \\
\hline \multirow[t]{3}{*}{1} & (Constant) & 1.780 & 0.283 & & 6.285 & 0.000 & & \\
\hline & Addictive's & -0.587 & 0.198 & -0.312 & -2.970 & 0.004 & 0.853 & 1.173 \\
\hline & $\begin{array}{l}\text { Time spent } \\
\text { for study }\end{array}$ & 0.301 & 0.093 & 0.339 & 3.224 & 0.002 & 0.853 & 1.173 \\
\hline
\end{tabular}

In Table 12, the collinearity statistics shows the existence of multicollinearity in the model of academic performance. It is demonstrated that the variance inflation factor (VIF) is exceedingly small, which is to indicate the absence of the problem if multicollinearity presents in the data. The tolerance of both variables is closer to one, which implies that the variables are not collinear with each other.

The estimated model is $\hat{y}_{\mathrm{k}}=1.780-0.587 \mathrm{D}_{\mathrm{k}}+0.301 \mathrm{X}_{\mathrm{k}}$, where the dummy variable is 1 .

i.e $\mathrm{E}(\mathrm{yk} / \mathrm{xk}, \mathrm{Dk}=1)=1.780-0.587(1)+0.301 \mathrm{X}_{\mathrm{k}}=1.193+0.301 \mathrm{X}_{\mathrm{k}}$

Where $\mathrm{Y}_{\mathrm{k}}=$ students' academic performance that uses stimulants

$$
\mathrm{X}_{\mathrm{k}}=\text { time spent for study }
$$


$>\hat{\mathrm{y}}_{\mathrm{k}}=1.780-0.587 \mathrm{D}_{\mathrm{k}}+0.301 \mathrm{X}_{\mathrm{k}}$, where the dummy variable is 0 , means that the students does not use stimulants (not addicted).

$\mathrm{E}(\mathrm{yk} / \mathrm{xk}, \mathrm{Dk}=0)=1.780-0.587(0)+0.301 \mathrm{X}_{\mathrm{k}}=1.780+0.301 \mathrm{X}_{\mathrm{k}}$

Where $\mathrm{Yk}=$ academic performance of students that do not use stimulants

$$
\mathrm{X}_{\mathrm{k}}=\text { time spent in the study }
$$

The models shows that the academic performance of students who use addiction differ from the academic performance of the students who do not use addiction.

Moreover, $\delta_{0}=-0.587$ demonstrated that the academic performance of the addicted group differs from nonaddicted groups by 0.587 on the same academic subjects. As these regression results shows, the mean academic performance of students who do not use stimulants were 1.780 and that of students who were evolved in addiction is lower by 0.587 holding the study time constant. As can be seen from this regression, the estimated slope is statistically significant at $4 \%$. Therefore, the overall conclusion is that the academic performance of students that were evolved in addiction were statistically significantly lowered by 0.587 .

\section{DISCUSSION}

Whenever a student attends a school of any kind anywhere, where learning is applied, the family of such a student is usually worried about the achievement of the student. Some may even extend their worries to the level of achievement. We take a positive view of the achievements in this situation. Accordingly, the education and training policies applied in Ethiopia has addressed a number of issues to standardize students' academic achievement. Concerning this point, there seems a gap between what ought to be and what exists in reality to bring in the intended outcomes of academic achievement that could be because of different factors.

According to Parker et al.. [13] [14] [15], parents are far more influential over their children's education progress. Besides families, community partnership should be considered as a valuable force for students academic years to encompass social and emotional learning, helping them develop skills so to become succeed academically and emotionally. This plays an important role 
in coordinating and managing phases due to its vitality for the improvement of student achievement.

From the results of the present study, it was observed that most of the students were evolved in addiction and male students occupied the largest part 57(73.1\%) in comparison to females 21(26.9\%). Males were found to be more vulnerable to addiction in there academic years than females in the present study is in line with the male preponderance for substance use report conducted elsewhere [16]. Men are often self-centered and prone to taking risks. Drug use by men is also common, and female use is a tradition in many societies. Although prices are low for women, their side effects can be very serious due to biological differences [17].

Among the selected respondents, practicing addiction knowingly or unknowingly is much greater than respondents not aware of any addiction. Based on preference to addiction, 56(71.8\%) were found to be engaged in one or more types of addictions, while the rest 22(28.2\%) were found to be addicted not to any kind of substances and free from any type of addictions.

It was found that most of the respondents identified as addicted to various kinds of stimulants based on preference and accessibility. Most of the respondents 18(32.1\%) were found to use coffee before or after class every day. The minimum number $4(7.1 \%)$ of the respondents addicted to computer games where as, 15(26.8\%), 10 (17.9\%), and 9 (16.1\%) identified as khat, alcohol and other social networks and porn respectively for varied reasons. Consumption of coffee is a common and widely practiced kind of stimulant by the students in universities of Ethiopia. In line with the present study, other similar studies reported that the overall prevalence of substance use among Wolaita Sodo University students was $28.6 \%$ and for those who use substances, $86.5 \%$ use alcohol, $35.7 \%$ use khat, and $19.8 \%$ use tobacco products [18].

The overall consumption of alcohol was $17.9 \%$ in the present study which is in line with the study carried out in different higher education institutions of Ethiopia; it was $21.6 \%$ among medical students of Addis Ababa University, 20\% in Haramaya University students, 21.7\% in college students of Southern Ethiopia and 32.8\% in Axum University students [11] [19] [20]. However, the finding in this study was lower than all mentioned university students degree of alcohol consumption. 
On the contrary to the present study, a study from Sudan, a predominantly Muslim country that follows strict Sharia law, has reported a very small 2.7\% increase in current alcohol consumption among university students [21]. These findings are consistent with a report from Iran, another Islamic country, which reported $6.9 \%$ alcohol use among university students [22]. Religion plays a major role in reducing drug abuse.

Students use stimulants for different reasons. From the present study, it was observed that most of the respondents $31(55.4 \%)$ use stimulants to relaxation and refresh themselves and the minimum number $2(3.6 \%)$ of respondents filled in addiction by peer pressure were as $18(32.1 \%)$, $5(8.9 \%)$ are use stimulants to improve reading and understanding and to spend there time, respectively. Most of the respondents used stimulants for relaxation and stress management that was created during reading and other related work loads. Relationship and break-up were mentioned as a key factor that triggered the use of stimulants.

Different studies conducted in different universities show that the reasons for psychoactive substance use among students' were joining the university, which may often lead to new opportunities, independence from family control, self-decision making, and peer pressure to use or abuse alcohol or other drugs [10] [23]. Other findings also pointed out the factors for student drug use as the early use of drugs for healing purposes and religious ceremonies, psychological stressors related to the demand to adapt to a new environment, and educational challenges/academics, lack close supervision as university life liberates many university students from their parental control, to make friendship and peer pressure [11] [24] [25] [26] [27] [28] [29] [30].

Other similar factors reported were: study duration and length of stay in university [10] [27], having alcohol with family members [11] [29], search for pleasure and enjoyment [20] [27] [28] [31], cultural influences (using alcohol as part of traditional practices) especially for students from the eastern part of Ethiopia [27], to get rid of stress and depression [10] [20] [31] [32], keeping alert while reading and to increase performance [31] [25] [27], lacking sufficient, attractive and alternative means of recreation in the university compound [26], easy availability of substance around the university surrounding [26], living alone [29], academic dissatisfaction and lack of interest to the field of study [28], having more than enough pocket money [33] [34] and living off the campus [35]. 
In line with the present study, the psychological factors which contribute to drug use are to perform better in the academic area, to reduce stress, to become happy, and to the ideology that "taking the drug is normal" [36]. This finding is also similar to the findings of different studies conducted in different universities showing that the reasons for psychoactive substance use among students' were to increase performance on reading for long hours, pleasure, socialization, to avoid tension, accessibility of drugs, peer pressure [30] [37] [38] [39].

The academic performances of students and there income were found to be interrelated $(\mathrm{P}=$ 0.0199) and there is an association between income of the family with the academic achievements of the students. Lack of enough finance halts the need of students and makes them dependent on other students of similar academic level. This may dismay or depress the courage and energy to participate in group work and reading for the fear of being undermined and shyness. Having more than enough pocket money also forces the students to practice consumption of alcohol and other illicit substances, chewing khat, smoking cigarette/shisha, and other higher level addictives. The parental income and emotional intelligence shall significantly affect the academic achievement of students in the present study is in line with the evidence of Parker et al.. [13] [14] [15] who retreated the relationship between emotional intelligence and academic success of students. According to Abisamra [40], there is a positive relationship between emotional intelligence and academic achievement, in line with the present study.

The academic achievement of students and the time given for the study are dependent $(\mathrm{P}=$ 0.003) and there is a perfect association between them. When students waste more time in reading academic materials, there the achievement becomes good as well. However, spending countless hours in addiction, failing to perform academic tasks well, social and spiritual responsibilities, and isolation are good indicative behaviors of addiction associated with poor academic performance. Someone who is addicted to any kind of stimulant feels like a mysterious, two-dimensional person who lives his life and keeps secrets from his friends and people he loves. He lied with his family and friends about the whereabouts of his family and friends.

According to the present study, the status of using stimulants and academic achievement are dependent. Using stimulants have adverse affect on the academic performance of the students. In line with the present study, other similar studies reported the status of using the substance and its 
association with mental distress and negative effects on academic performance [33] [41] [42] [43]. In addition to the mental and academic effects of an illicit substances, conflicts may exist between drug users and with there parents or friends along with chronic health-related problems, financial hardships, and other emotional disturbance [44] [45].

Studies showed that people who suffer from depression and anxiety are often addicted to any kind of stimulants [46]. If students become addicted, he or she will develop a strong interest in stimulants. In addition, the time he or she spends on it increases and finds no time to read handouts, referring notebooks, and doing assignments and project work and finally skip the classes and miss exams, tests, and quizzes as well as continuous assessments.

Students affected by addiction have a distorted the view of themselves and develop negative and discouraging thoughts to them. Such self-destructive self-esteem can lead to serious mental and psychological illness. A person who has a distorted the view of himself cannot be fair about people. Therefore, to reduce stress and to become happy, they start to play with addictions, watching pornography, and other drug abuses and the users find the desired pleasure and enjoyments for short time but never escape the emotional disorder they are feeling like anxiety, depression, sadness, fear and shame. Therefore, those who are depressed and unresolved in their lives use it to grieve and to find temporary happiness. It has been found that students who watch pornography at university often find that they hate their learning and education of their interest.

Pornography is a neglected silent drug which has a potential to make people addictive, and college students are the more vulnerable group due to an open access, broadband internet connection, and wireless internet fidelity (Wi-Fi) service. They look at pornography in terms of looking for something that is both enjoyable and entertaining, just as people watch any kind of movie [47] [48]. Frequent consumption of pornographic videos, images, animations, and texts has an adverse effects on the academic achievement of students. Often porn materials penetrate into the user's account and students are perturbed differently. Sometimes porn materials also appear suddenly on the screen through pop-ups and students react unpredictably on these occasions. Such an immense availability and sudden penetration of pornography has also led to the spread of addiction. 
Social scientists, medical psychologists, and biologists have begun to explain some of the social and psychological effects of pornography, and neurologists are beginning to identify biological mechanisms by which pornography releases its powerful effects on humans. Evidence from neurobiological studies fits pornography addiction as the general addiction framework, and share similar mechanisms with those observed in addictions to chemical substances [49] [50] [51] [52] although controversies in this regard exist [51] [53] and some alternative models based on compulsivity, impulsivity or moral incongruence were suggested to describe high and problematic consumption of pornography [53].

\section{Conclusion}

Based on the results of the study, it could be concluded that addiction has a negative effect on the academic performance of students. Time of study and academic performance of the students are strongly related, i.e., addiction and study time of the students is dependent. The status of using stimulants depends on the academic performance of students. Addiction also affects the study time of the students, disorder of the sleeping time, relation with their friends, and mental function. In this study, males were more vulnerable to addiction than females. The reasons for the use of stimulants were relaxation and refreshment, improvement of reading, and understanding to spend time. Students start using stimulants for these reasons and forced by three peers to do so. The academic performances of the students who use stimulants were less than the academic performances of the students that did not use stimulants. Drinking coffee, chewing khat, social networks, and porn as well as computer games were mentioned as some of the stimulants. The effects of addiction might be better studied through pertinent, vigorous research. Such research will assist parents, educators, policy makers, health professionals, and law enforcement in fostering and supporting the healthy development of students, while minimizing the risk potential for negative effects related to addiction.

\section{Recommendation}

Current smoking, khat chewing, drinking alcohol, and other illicit substances have significantly increased risks that are associated with poor grading. The high prevalence of substance use and its association with poor academic performance demand from universities to have a good control of substance and to implement youth friendly activities to bring behavioral change in their 
students. In view of the findings of the study and the conclusions drawn, the following recommendations were forwarded:-

Parents and religious bodies should contribute to enhance the behavioural patterns of students in college as regards drug use to curtail the societal ills associated with drug abuse. Students should avoid to the use of stimulants to improve their academic achievement. To avoid the impact of addiction, students should have to use alternative means to the reasons mentioned in the use of addiction so to avoid the impact of addiction on their academic performance during learning.

The Ministry of Science and Higher Education and Ministry of Science and Technology in collaboration with the Ministry of Health and all other concerned bodies including Drug Control Commission, Information and Cyber Security Agency and Police Service's drug abuse and stimulant controlling units starting from parliament should initiate comprehensive programmes that may engage the youth within the college more active on alternative means such as tree planting, sporting activities and voluntary programmes like anti-drug abuse clubs, cleaning the environment etc, which may minimise idleness. Along with above-mentioned bodies, the university's ICT directorate should work with artificial intelligence and algorithms to trawl various online platforms for pornographic audio, photos, and videos with remarkable accuracy. Some pornographic magazines, namely, Zibad, Yefikir-Enken, Yefikir-Chawota, Affrodait, Eyor, Emagn, and Afla-Fikir were magazines that have been published between 1985-1987 EC were banned from the market since 1990 E.C. Similarly, banning should extend to recent online and print medias and magazines described as "rubbish" because they have been damaging and polluting the psychological, mental, emotional, behavioral, and sexual health of the youth and children in the country as whole.

The ministry of Science and Higher Education should introduce clear policies on drug abuse prevention to all learning institutions, making them to have programmes such as having regular visits for guest speakers in colleges. All higher educational institutions ought to have a strategic academic plans for the whole year and copies should be submitted to the Ministry of Science and Higher Education of the country. The college administrators should be strict on school drug policy and have special offices dealing with drug abuse.

Ministry of Science and Higher Education should have a strict policy that student level of satisfaction be investigated on admission, reasons identified, and counselling done where 
necessary. A student's character assessment should be used yearly to test different dimensions such as discipline, academics, and relationship with teachers and students, among others.

Local film production industries, actors, writers, and directors should be encouraged to produce culturally sound [decent] world-class movies free from smoking and drug abuse to keep Ethiopian culture and young people's drug abuse, addiction and sexual health sustained rather than worsening.

\section{Abbreviation}

M: $\quad$ number of clusters (colleges) in university

ANOVA: Analysis of variance

COTM: $\quad$ construction management

VIF: $\quad$ variance inflation factor

Wi-Fi: Wireless internet fidelity

ICT: Information and communications technology

WHO: $\quad$ World Health Organization

\section{Limitations}

This study did not include substances other than tobacco products, alcohol, and khat. Interaction effect of these substances on academic achievement was also not assessed. The sample size was very low due to financial constraints. Other similar studies in different parts of the country are suggested.

\section{Declaration of interests}

The authors declare that they have no known competing financial interests or personal relationships that could have appeared to influence the work reported in this paper.

\section{Declarations}

We confirm that this work is original and has not been published elsewhere, nor is it currently under consideration for publication elsewhere. 


\section{Ethical considerations}

Ethics approval is not applicable. Although these studies present a minimal risk to participants, it has been conducted in accordance with the Declaration of Helsinki that provides guidance for the researcher to protect research subjects. Oral informed consent was obtained before the interviews. The objective of the research were explained to all respondents in brief.

\section{Consent to participation}

Not applicable

\section{Consent to publication}

All authors agreed to the public this original research work

\section{Competing interests}

The authors declare that they have no competing interests

\section{Funding statement}

The authors declare that no specific funding from any fundraising organizations.

\section{Authors' contribution statement}

All authors contributed to the study conception and design. Material preparation, data collection, and analysis were performed by Elias Bojago and Abenezer Wendimu. All authors read and approved the final manuscript.

\section{Acknowledgments}

We would like to acknowledge Wolaita Sodo University for giving permission to do this research. We also thank the respondents for willingness to take part in this study.

\section{Availability of data and materials}

The data generated and analyzed during the current study is included in the body of this paper.

\section{References}

1. Birhanu MA. Transforming educational practices of Ethiopia into development and the knowledge society through information and communication technology. African educational research journal 2017;5(1):1-17. https://files.eric.ed.gov/fulltext/EJ1216159.pdf

2. Melesse M. Stockholders views about preparation for implementation of school improvement program. Research in pedagogy 2016;2:72-84. https://www.ceeol.com/search/articledetail $? \mathrm{id}=472988$ 
3. Aklog GT, Girmay TT. Assessment of substance abuse and associated factors among students of debre markos polytechnique college in debre markos town, East Gojjam Zone, Amhara Regional State, Ethiopia, 2013. Global journal of medical research 2013;13:4. https://medicalresearchjournal.org/index.php/GJMR/article/view/377\#

4. Manish G, Deepali T, Neetu S. Effect of the drug abuse on the academic performance of the students/adolescents. Biomedical journal of science and technological research 2020;28(3). https://dx.doi.org/10.26717/BJSTR.2020.28.004652

5. Sullivan EV, Harris RA, Pfefferbaum A. Alcohol's effects on brain and behavior. Alcohol research and health 2010;33(1-2): 127-143. https://www.ncbi.nlm.nih.gov/pmc/articles/PMC3625995/

6. Clapp P, Bhave SV, Hoffman, PL. How adaptation of the brain to alcohol leads to dependence. Alcohol research and health 2008;31(4): 310-339. https://www.ncbi.nlm.nih.gov/pmc/articles/PMC2923844/

7. Bakar C, Gundogar D, Karaman HI, Maral I. Prevalence and related risk factors of tobacco, alcohol and illicit substance use among university students. European journal of psychiatry 2013;27(2): 97-110. https://dx.doi.org/10.4321/S0213-61632013000200003

8. Sahraian A, Sharifian M, Omidvar B, Javadpour A. Prevalence of substance abuse among the medical students in southern Iran. Shiraz. E Medical Journal 2010;11(4): 198-202. [Google scjolars]

9. van Heerden MS, Grimsrud AT, Seedat S, Myer L, Williams DR, Stein DJ. Patterns of substance use in South Africa: results from the South African stress and health study. South African medical journal 2009;99(5): 358-366. https://pubmed.ncbi.nlm.nih.gov/19588799/

10. Deressa W, Azazh A. Substance use and its predictors among undergraduate medical students of Addis Ababa University in Ethiopia. BMC public health 2011;11:660. https://doi.org/10.1186/1471-2458-11-660

11. Gebreslassie M, Feleke A, Melese T. Psychoactive substances use and associated factors among Axum University students, Axum Town, North Ethiopia. BMC public health 2013;13(1): 693. https://doi.org/10.1186/1471-2458-13-693 
12. Reda AA, Moges A, Biadgilign S, Wondmagegn BY. Prevalence and determinants of khat (Catha edulis) chewing among high school students in eastern Ethiopia: a cross-sectional study. PLoS ONE 2012;7(3): e33946. https://dx.doi.org/10.1371\%2Fjournal.pone.0033946

13. Parker JDA, Summerfieldt LJ, Hogan MJ, Majestic S. Emotional intelligence and academic achievement. A paper presentation at the annual meeting of the Canadian psychological association, Quebec City, Quebec. 2001. [Google scholars]

14. Parker JDA, Creques R, Harris J, Majeski SA, Wood LM, Hogan, MJ. Academic success in high school: does emotional matter? ERIC Clearing House. 2003. [Google scholars]

15. Parker JDA, Summerfield LJ, Hogan MJ, Majeski S. Emotional intelligence academic success: examining the transition from high school to university. Personality and individual difference 2004;36(1):163-172. ((https://doi.org/10.1016/S0191-8869(03)00076-X

16. Wedegaertner F, al-Warith H, Hillemacher T, teWildt B, Schneider U, Bleich S, et al. Motives for khat use and abstinence in Yemen-a gender perspective. BMC public health 2010;10:735. https://doi.org/10.1186/1471-2458-10-735

17. Bobzean SAM, DeNobrega AK, Perrotti LI. Sex differences in the neurobiology of drug $\begin{array}{lll}\text { addiction. } & \text { 2014;259:64-74. }\end{array}$ https://doi.org/10.1016\%2Fj.expneurol.2014.01.022

18. Mekonen T, Fekadu W, Mekonnen TC, Workie, SB. Substance use as a strong predictor of poor academic achievement among university students. Hindawi psychiatry journal. 2017. Article ID 7517450, 9 pages. https://doi.org/10.1155/2017/7517450

19. Samuel L, Angamo MT. Substance use and sexual risk behavior and factors associated with HIV transmission in southern Ethiopia. International journal of pharmaceutical science and research 2012;3:1080-1086. http://dx.doi.org/10.13040/IJPSR.0975-8232.3(4).1080-86

20. Tesfaye G, Derese A, Hambisa MT. Substance use and associated factors among university students in Ethiopia: across-sectional study. Journal of addiction 2014;969837:1-8. https://doi.org/10.1155/2014/969837

21. Osman T, Victor C, Abdulmoneim A, Mohammed H, Abdalla F, Ahmed A, et al. Epidemiology of substance use among university students in Sudan. Journal of addiction. 2016;2476164:1-8. https://doi.org/10.1155/2016/2476164 
22. AAbbasi-Ghahramanloo A, Fotouhi A, Zeraati H, Rahimi-Movaghar A. Prescription drugs, alcohol, and illicit substance use and their correlations among medical sciences students in Iran. International journal of high risk behaviors \& addiction 2015;4(1):e21945. https://dx.doi.org/10.5812\%2Fijhrba.21945

23. Gebresilassie TA, Hadush, KZ, Gidey LG, Hagos GW, Mussie WM, Gebregiorgis AG, et al. Prevalence of factors associated with and level of dependence of psychoactive substance use among Mekelle University Students, Ethiopia. International journal of environmental research and public health 2020;17(3):847. https://pubmed.ncbi.nlm.nih.gov/32013178/

24. Teferi KA. Psychoactive substance abuse and intention to stop among students of Mekelle University, Ethiopia. MPH thesis. 2011. [Google scholars]

25. Mamo DB, Abuhay DA, Gelaw BK, Tegegne GT. Assessment on the prevalence and contributing factors of social drugs utilization among university of Gondar regular undergraduate students, Maraki campus. International journal of pharmaceutical sciences and research 2013:5(8):518-30. [Google scholars]

26. Kumburi GT, Gelgile AK, Hatehu, BT, Gemechu DT. Psycho-active substances use and determining factors among regular undergraduate students of Dire-Dawa University, eastern Ethiopia. Science journal of public health 2017;5(2):68-76. [Google scholars]

27. Teshome M, Gupta S. Substance abuse and its impacts on undergraduate student's academic performance (Students of Adama Science and Technology University in Focus). International journal of scientific research in computer science, engineering and information technology 2017;2(3): 452-461. https://1library.net/document/zp2w5koy-substance-impacts-undergraduateacademic-performance-students-technology-university.html

28. Hagos EG, Asfeha GG, Berihu BA. Prevalence of substance abuse among regular degree health science students in Sheba University College in Mekelle town, Tigray. Ethiopian journal of neuroscience and rural practice 2016;7(2): 200-5. https://pubmed.ncbi.nlm.nih.gov/27114648/

29. Kassa A, Wakgari N, Taddesse F. Determinants of alcohol use and khat chewing among Hawassa University students, Ethiopia: a cross sectional study. African health science 2016;16(3):822-30. https://dx.doi.org/10.4314\%2Fahs.v16i3.24 
30. Likisa KD. The prevalence of student's drug addiction in higher learning institutions: a comprehensive review of literature. Ethiopian journal of sciences and sustainable development 2019;6(2):33-45. [Google scholars]

31. Ahmed M. Prevalence of substance use and its determinants among Rift Valley University College students in Adama, Ethiopia. Proceedings of the 5th national research conference on research for quality and relevant higher education and training 2013;49-60. [Google scholars]

32. Birhanu B. The relationship between stress, coping behaviour and substance abuse among Debreberhan University students.MA thesis, Addis Ababa University. 2014. https://www.etd.aau.edu.et/handle/123456789/3857

33. Meressa K, Mossie A, Gelaw Y. Effect of substance use on academic achievement of health officer and medical students of Jimma University, southwest Ethiopia. Ethiopian journal of health science 2009;19(3):155-63. https://www.ajol.info/index.php/ejhs/article/view/145811

34. Adere A, Yimer NB, Kumsa H, Liben ML. Determinants of psychoactive substances use among Woldia University students in northeastern Ethiopia. BMC research notes 2017;10:441. https://doi.org/10.1186/s13104-017-2763-X

35. Gebrehanna E, Berhane Y, Worku A. Khat chewing among Ethiopian university students- a growing concern. BMC public health 2014;14:1198. https://doi.org/10.1186/1471-2458-14-1198 36. Gebresellasie M. The assessment of causes and consequences of drug use among Wollo University students. IOSR Journal of humanities and social science 2020;25(9):17-28. https://www.iosrjournals.org/iosr-jhss/papers/Vol.25Issue9/Series-8/C2509081728.pdf

37. WHO (World Health Organization). Global status report on alcohol. 2004. [Google scholars]

38. Mulugeta Y. Khat chewing and its associated factor among college students in Bahir Dar Town, Ethiopia. Science journal of public health 2013;1(5):209-14. https://doi.org/10.11648/j.sjph.20130105.14

39. Njoroge M, Kenyatta J. Knowledge, attitude and practices on substance use disorders by university students: a review of the literature. Journal of alcoholic drug dependence 2017;5(2). https://www.longdom.org/open-access/knowledge-attitude-and-practices-on-substance-usedisorders-by-university-students-a-review-of-literature-2329-6488-1000291.pdf 
40. AbiSamra N. The relationship between emotional intelligent and academic achievement in eleventh graders. Research in education, FED. 661. Aremu, A.O. 2000. https://www.nadasisland.com/research-intell2.html

41. Mancevska S, Bozinovska L, Tecce J, Pluncevik-Gligoroska J, Sivevska-Smilevska E. Depression, anxiety and substance use in medical students in the Republic of Macedonia. Bratislava medical journal 2008;109(12):568-572. https://pubmed.ncbi.nlm.nih.gov/19348380/

42. Damena T, Mossie A, Tesfaye M. Khat chewing and mental distress: a community based study, in Jimma city, southwestern Ethiopia. Ethiopian journal of health sciences 2011;21(1):3745. https://dx.doi.org/10.4314\%2Fejhs.v21i1.69042

43. Dessie Y, Ebrahim J, Awoke T. Mental distress among university students in Ethiopia: a cross sectional survey. Pan African medical journal 2013;15:95. https://dx.doi.org/10.11604\%2Fpamj.2013.15.95.2173

44. Abdu-Raheem BO. Sociological factors to drug abuse and the effects on secondary school students academic performance in Ekiti And Ondo States, Nigeria. Contemporary issues in education research (CIER) 2013;6(2):233. https://doi.org/10.19030/cier.v6i2.7733

45. Tsvetkova LA, Antonova NA. The prevalence of drug use among university students in St. Petersburg, Russia. Psychology in Russia: state of the art 2013;1:86-94. https://doi.org/10.11621/pir.2013.0108

46. Mohamed II, Ahmad HEK, Hassaan SH. et al. Assessment of anxiety and depression among substance use disorder patients: a case-control study. Middle east current psychiatry 2013;27:22. https://doi.org/10.1186/s43045-020-00029-w

47. FTND (Fight the new drug). Five basic reasons why people choose to look at porn. 2019. Retrieved on March 9, 2020 from https://fightthenewdrug.org/basic-reasons-why-people-look-atporn/

48. Amanuel T. The Influence of Exposure to Pornography among the Youth in Addis Ababa. (Unpublished Master's thesis, Addis Ababa University, Addis Ababa, Ethiopia). 2007. Retrieved $\begin{array}{llll}\text { on } & \text { March } & \text { 9, } & \text { from }\end{array}$ https://pdfs.semanticscholar.org/2e4a/003ae4d2fad17f8e6fa5e72f027ca170770d.pdf 
49. Brand M, Young KS, Laier C. Prefrontal control and Internet addiction: A theoretical model and review of neuropsychological and neuroimaging findings. Prefrontal control across psychiatric disorders 2014;8:375. https://doi.org/10.3389/fnhum.2014.00375

50. Kühn S, Gallinat J. Brain structure and functional connectivity associated with pornography consumption: the brain on porn. JAMA psychiatry 2014;71:827-834. [Google scholars]

51. Love T, Laier C, Brand M, Hatch L, Hajela R. Neuroscience of internet pornography: a review and update. Behavioral science 2015;5:388-433. https://doi.org/10.3390/bs5030388

52. Klucken T, Wehrum-Osinsky S, Schweckendiek J, Kruse O, Stark R. Altered appetitive conditioning and neural connectivity in subjects with compulsive sexual behavior. The Journal of sexual medicine 2016;13:627-636. https://doi.org/10.1016/j.jsxm.2016.01.013

53. Ley D, Prause N, Finn P. The Emperor has no clothes: a review of the "pornography addiction" model. Current sexual health reports 2014;6:94-105. https://doi.org/10.1007/s11930$\underline{014-0016-8}$ 